\title{
Antarktika'da Küresel İklim Değişikliği İzleme için GNSS İstasyon Tasarımı: TUR1 ve TUR2 GNSS İstasyonlarının 4. Ulusal Antarktika Bilim Seferi'nde Antarktika Horseshoe Adası'na Kurulumu
}

\author{
Mahmut Oğuz SELBESOĞLU ${ }^{1 *}$, Hasan Hakan YAVAŞOĞLU², Mustafa Fahri KARABULUT², Hüseyin \\ Ayhan YAVAŞOĞLU ${ }^{4}$, Hüseyin Günhan ÖZCAN ${ }^{5}$, Özgün OKTAR², Burcu ÖZSOY², Himmet \\ KARAMAN ${ }^{1}$, Mustafa Ersel KAMAŞAK ${ }^{6}$, Vahap Engin GÜLAL ${ }^{7}$ \\ ${ }^{1}$ Isstanbul Teknik Üniversitesi, Inşaat Fakültesi, Geomatik Mühendisliği Bölümü, İstanbul. \\ ${ }^{2}$ TÜBITAK, Marmara Araştırma Merkezi, Kutup Araştırmaları Enstitüsü, Kocaeli. \\ ${ }^{3}$ Yıldız Teknik Üniversitesi, Inşaat Fakültesi, Harita Mühendisliği Bölümü, İstanbul. \\ ${ }^{4}$ TÜBіTAK, Raylı Ulaşım Teknolojileri Enstitüsü, Robotik ve Akılı Sistemler Bölümü, Kocaeli. \\ ${ }^{5}$ Yaşar Üniversitesi, Mühendislik Fakültesi, Enerji Sistemleri Mühendisliği Bölümü, İmir. \\ ${ }^{6}$ istanbul Teknik Üniversitesi, Bilgisayar ve Bilişim Fakültesi, Bilgisayar Mühendisliği Bölümü, Istanbul. \\ ${ }^{7}$ Atlas Üniversitesi, İstanbul.
}

*Sorumlu Yazar, e-posta: selbesoglu@itu.edu.tr,

ORCID ID: https://orcid.org/0000-0002-1132-3978

hakan.yavasoglu@tubitak.gov.tr, ORCIDID: https://orcid.org/0000-0002-3139-4327

mfahri@yildiz.edu.tr,

ORCID ID: https://orcid.org/0000-0001-8513-3475

huseyin.yavasoglu@tubitak.gov.tr,ORCID ID: https://orcid.org/0000-0001-8145-719X

huseyin.ozcan@yasar.edu.tr, ozgun.oktar@tubitak.gov.tr, ORCID ID: https://orcid.org/0000-0002-8639-6338 burcu.ozsoy@tubitak.gov.tr, ORCID ID: https://orcid.org/0000-0002-0188-6267 karamanhi@itu.edu.tr, kamasak@itu.edu.tr, engin.gulal@atlas.edu.tr, ORCID ID: https://orcid.org/0000-0003-4320-1796 ORCID ID: https://orcid.org/0000-0003-4923-3561 ORCID ID: https://orcid.org/0000-0002-5050-3357 ORCID ID: https://orcid.org/0000-0002-5397-3303

Geliş Tarihi: 02.06.2021 Kabul Tarihi: 09.11.2021

Öz

Son yıllarda uzay tabanlı konumlama sistemleri, GNSS Meteorolojisi ve GNSS Reflektometresi teknikleri kullanılarak gözlemlenen atmosferik su buharı, deniz, buz ve kar seviyeleri gibi önemli parametrelerle küresel iklim değişikliğinin izlenmesinde etkili bir destekleyici araç haline gelmiştir. Küresel ölçekte tüm

Anahtar Kelimeler GNSS Meteorolojisi; GNSS-R; Antarktika; Troposfer; Buzul; Deniz Seviyesi; Su Buharı bölgelerden daha hızlı ısınan Antarktika'da iklim değişikliğini incelemek, gelecekteki iklim değişikliğini daha doğru tahmin etmek için çok önemlidir. Dünya'nın iklim değişikliği etkilerinin izlenebilmesi amacıyla, 118Y322 No'lu TÜBiTAK projesi kapsamında GNSS Meteorolojisi ve GNSS Reflektometresi teknikleri ile 24 Şubat 2020 tarihinden itibaren Antarktika'da atmosferik su buharı değişimleri, kar derinliği ve buz kalınlığı değişimleri gözlemlenmektedir. Bu çalışmada, Troposfer ve Deniz Seviyesi Gözlem İstasyonu (TUR1) ile Troposfer ve Kar / Buz Seviyesi Gözlem i̇stasyonunun (TUR2) tasarım çalışmaları ve 4. Ulusal Antarktika Bilim Seferi'nde Antarktika Horseshoe Adası'na kurulum aşamaları anlatılmıştır. Bu çalışmalar, meteorolojik koşullar, şebekeden bağımsız ve batarya ile bütünleşik enerji sisteminin en sağlıklı şekilde güneş ve rüzgâr enerjisinden beslenmesi ve bölgede oluşabilecek buzul oluşumu ve kayaç parçalanması gibi jeolojik parametreler de göz önüne alınarak yapıımıştır.

\section{GNSS Station Design for Global Climate Change Monitoring in Antarctica: Installation of TUR1 and TUR2 GNSS Stations on Horseshoe Island in Antarctica During the 4th Turkish Antarctic Science Expedition}


GNSS Meteorology; GNSS-R; Antarctica; Troposphere; Glacier; Sea Level; Water Vapor
In recent years, space-based positioning systems have become an effective supporting tool for monitoring global climate change by important parameters such as atmospheric water vapor, sea, ice and snow levels observed by using GNSS Meteorology and GNSS Reflectometry techniques. Studying climate change in Antarctica, which is warming faster than all of the regions on a global scale, is very important to predict future climate change more accurately. In order to monitor climate change effects of the Earth, tropospheric water vapor variations, snow depth and ice thickness changes have been observing in Antarctica since 24 February 2020 by means of GNSS Meteorology and GNSS Reflectometry techniques within the scope of the TUBITAK Project No. 118 Y 322 In this study, designing studies of Troposphere and Sea Level Observation Station (TUR1) and Troposphere and Snow / Ice Level Observation Station (TUR2) and installation steps to Horseshoe Island in Antarctica during the 4th National Antarctic Science Expedition are explained. These studies was carried out by taking into account the meteorological conditions, the healthiest feeding of the off grid battery integrated energy system from solar and wind energy and geological parameters such as glacial formation and rock fragmentation that may occur in the region.

(C) Afyon Kocatepe Üniversitesi

\section{Giriş}

Dünya'nın doğal laboratuvarı olan Antarktika Kıtası, iklim değişikliklerinin gözlemlenmesi ve zaman içindeki evrimi ile yerel ve küresel değişimi anlamak ve tahmin etmek için oldukça önemli bir bölgedir. Bölge ve çevresinde gerçekleştirilen Jeodezi tabanlı bilimsel çalışmalarda, uzay ve yer tabanlı olmak üzere birçok gözlem tekniği kullanılmaktadır. Bu kapsamda, uydu sinyallerine dayalı olmak üzere mekânsal verinin üretilmesi, deniz seviyesinin izlenmesi, kar/buz kalınlıklarının takibi gibi çalışmalar yapılmaktadır (Selbesoglu vd. 2018). Bunlarla beraber, uzaktan algılama ile görüntüleme, hidrografik ölçmeler ve gravite ölçmeleri gibi yöntemlerden de faydalanılarak küresel iklim değişikliğinin etkilediği fiziksel parametrelerin izlenmesi gerçekleştirilmektedir. Bu amaçla elde edilen sonuçlar, farklı disiplinlerin araştırmalarına da önemli bilgiler sunmakta ve bölgenin izlenmesine önemli katkılar sağlamaktadır. Antarktika Araştırmaları Bilimsel Komitesinin (Scientific Committee on Antarctic Research - SCAR) oluşturduğu bilimsel grupların altında yer alan GNSS (Global Navigation Satellite System) Research and Application for Polar Environment (GRAPE) araştırma programı, GNSS ağ kurulumu ve koordinasyonu için uluslararası katılım ile oluşturulmuştur. Bu kapsamda, University NAVSTAR Consortium (UNAVCO) tarafindan desteklenen kutup projeleri de yer almaktadır. Bu projelerde; Antarktika ve Arktik bölgelerinde olmak üzere GNSS ve sismik istasyonlarının kurulması, veri toplanması ve bunların yanında bazı istasyonlarda manyetik alan belirleme, gravite ölçmelerinin yapılması ve mareograf verilerinin de toplanması amaçlanmıştır. Bu kapsamda yapılacak bilimsel çalışmalar amacıyla POLENET (The Polar Earth Observing Network) ağı oluşturulmuştur. Bu ağda yer alan ve farklı projeler kapsamında kurulan GNSS istasyonları verilerinin değerlendirilmesi ile jeodinamik ve tektonik modelleme (Wu et al. 2006, Ye et al. 2014), buzul dinamiği çalışmaları (Thomas et al. 2011, Whitehouse et al. 2012), gravite çalışmaları (Li et 2019), atmosferin (troposfer ve iyonosfer) izlenmesi (Jayachandran et al. 2012, Li, F. et al. 2020, Li, H. et al. 2020, Wang et al. 2019) ve deniz seviyesinde (Tabibi et al. 2020) ve kıtada yer alan göllerin seviyesinde (Richter et al. 2014) meydana gelen değişimlerin belirlenmesi, kar ve buz kalınlık değişimlerinin belirlenmesi (Pinat et al. 2021) konularında çalışmalar yapılmakta, bu çalışmalar kıtanın geçmişi hakkında önemli bilgiler sunmakta ve kıtanın geleceği, dolayısıyla Dünya'nın geleceğine ışık tutmaktadır.

Bu çalışmalarda kullanılan istasyon tasarımları ve bileşenlerinin, çevresel koşullara bağlı olarak gözlem sonuçlarına etkisinin incelendiği çalışmalar da literatürde yer almaktadır (King et al. 2012, Koulali and Clarke 2020). Bu çalışmaların dışında, küresel iklim değişikliğinin izlenmesi için uzay tabanlı konumlama sistemleri ile yapılan bilimsel araştırmalar artarak devam etmektedir. 
Antarktika bölgesinde ülkemizin yürüttüğü çalışmalar, T.C. Cumhurbaşkanlığı himayesinde, Sanayi ve Teknoloji Bakanlığı uhdesinde ve TÜBITAK MAM Kutup Araştırmaları Enstitüsü (KARE) koordinasyonunda yapılan bilimsel seferlerle hızla gelişmeye devam etmektedir. Bu kapsamda 2017 yılında gerçekleştirilen Birinci Ulusal Antarktika Bilim Seferi (TAE-I) sonrasında oluşturulan Ulusal Kutup Bilim Programı (UKBP) (2018-2022) (Int Kyn. 1) çerçevesinde kıtada yapılacak bilimsel çalışmalara fon sağlanmaya, lojistik destek verilmeye ve düzenli seferler yapılmaya başlanmıştır.

UKBP kapsamında belirlenen öncelikli alanlar Fiziki Bilimler, Yer Bilimleri, Canlı Bilimleri ve Sosyal-Beşerî Bilimler olmak üzere 4 ana başlıktan oluşmaktadır. Bu bağlamda, Yer Bilimleri başlığı altında: Jeodezik Çalışmalar, Jeomorfoloji, Volkanoloji, MagmatizmaJeodinamik, Deniz/Göl Jeolojisi ve Jeofiziği, Buzul Çalışmaları, Yapısal Jeoloji, Jeodinamik Modelleme, Sismoloj yer almaktadır (Int Kyn. 1). Bu çerçevede, açılan TÜBITAK 1001 Kutup çağrıları ile Antarktika kıtasında yapılacak bilimsel projeler belirlenmektedir.

$118 Y 322$ nolu ve "Antarktika Bölgesinde Troposfer ve Kar Derinliğinin/Kalınlığının GNSS Meteorolojisi ve GNSS-Reflektometresi Yöntemleri ile İzlenmesi" başlıklı TÜBITAK projesi de bu kapsamda açılan çağrı ile desteklenmiştir. Bu çalışmada, Antarktika kıtası Horseshoe adası ve çevresinde, GNSS (Global Navigation Satellite System) Meteorolojisi tekniği ile atmosferik parametreler gözlemlenerek iklim değişikliği konusunda analizler yapılacaktır. Aynı zamanda, troposferik gecikme etkisinin elde edilmesinde kullanılan matematiksel ve ampirik modellerin (GPT2: Global Pressure and Temperature Model, UNB3M, VMF: Vienna Mapping Function, Niell Mapping Function, Saastamoinen Model vs.) araştırılması ve GNSS gözlemlerine getirilecek troposferik gecikme etkisinin hesabı gerçekleştirilecektir. Bununla birlikte, GNSSReflektometri (GNSS-R) tekniği ile kar/buz kalınlığı ve deniz seviyesi değişimi gibi bölgenin fiziksel karakteristiğini analiz etmede önemli parametreler izlenecektir. Ayrıca, kurulan sabit GNSS istasyonları ile bölgede oluşan tektonik deformasyonların izlenmesi ve farklı disiplinlerin bölgede yapacakları proje ve çalışmaları desteklemek için veri sağlanacaktır.

Bu çalışmada, TAE-4 seferi kapsamında Antarktika kıtası Horseshoe adasına kurulan 2 sabit GNSS istasyonunun kuruluş amacı, sistemin teknik detaylarının belirlenme süreci ve sefer süresince elde edilen verilerin ön sonuçlarından bahsedilecektir. Böylece, anılan bölgede diğer disiplinlerce yapılacak çalışmalar için kurulacak istasyonların hangi zorluklarla karşılaşabileceği ortaya konulabilecek, enerji, veri depolama ve iletimi gibi önemli kararların alınması kolaylaşacaktır.

\section{Materyal ve Metot}

\section{1 Çalışma bölgesi}

Çalışma bölgesi, Antarktika kıtasında, TAE seferlerinin yapıldığı ve sonrasında ülkemizin bilimsel üssüne ev sahipliği yapması planlanan Horseshoe Adasıdır. Yaklaşık olarak $67,83^{\circ}$ Güney enlemi ve $67,24^{\circ}$ Batı boylamında yer almaktadır (Şekil 1).

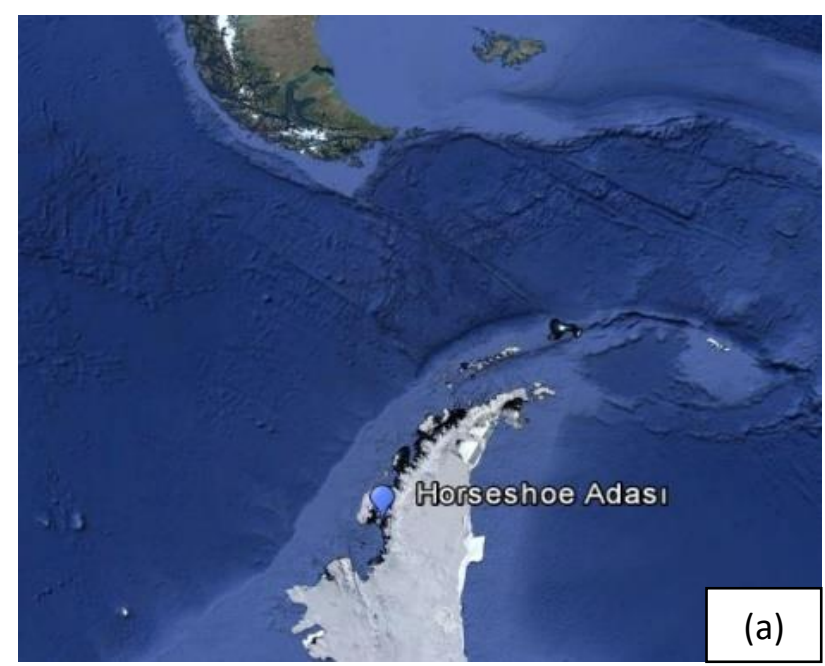




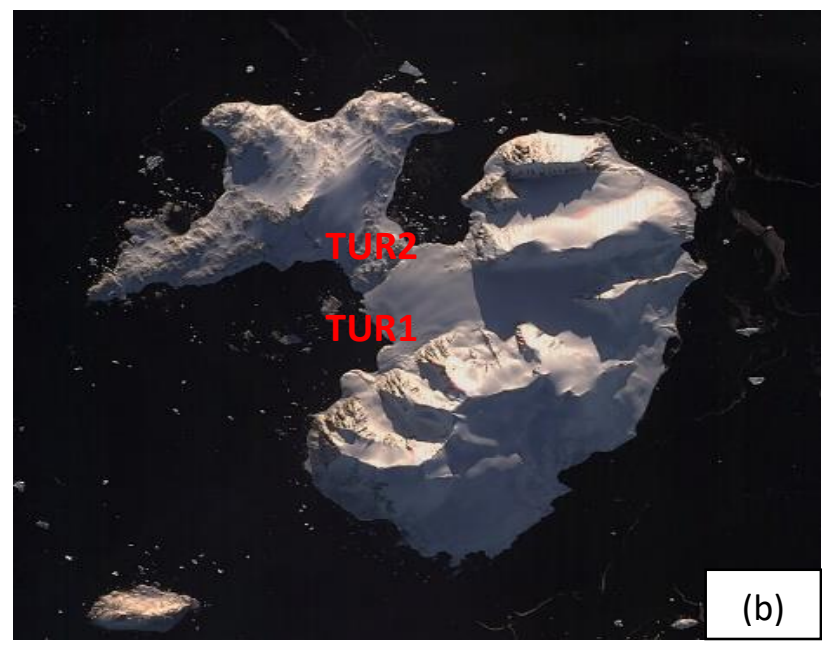

Şekil 1. (a) Antarktika (batı) yarımadası, (b) Çalışma alanı, Horseshoe adası, (1) TUR1 ve (2) TUR2'yi göstermektedir (Int Kyn. 2).

Çalışmanın gerçekleştirildiği alan, ulusal seferlerin bu adaya düzenlenmesi, ülkemiz üssünün yer alması planlandığı için bölgenin önem arz etmesi ve lojistik zorluklar göz önüne alınarak belirlenmiştir. Bununla birlikte, çalışmanın temelini teşkil eden ve özgünlüğünü oluşturan GNSS-R tekniği ile deniz ve kar/buz seviyesi değişimlerinin belirlenmesi, GNSS Meteorolojisi tekniği ile troposferin izlenmesi (su buharı) ve tektonik deformasyon çalışmaları amacıyla bu bölgede henüz istasyon/istasyonlar kurulmamıştır (Selbesoglu vd. 2018). Bu nedenle çalışma bölgesi, istasyonların kurulumu için uygun bir lokasyona sahiptir. Bununla birlikte, GNSS istasyonlarının enerji kaynağı için gerekli olan güneş panelleri ve rüzgâr türbinlerinin yön ve konumlarının hesapları için gereken yaklaşık değerlerin alınabileceği çevre istasyonlara komşuluk yapmaktadır. Arjantin'e ait San Martín istasyonu 35 km, Birleşik Krallık'a ait Rothera istasyonu 50 km ve Şili'ye ait Carvajal istasyonu ise $70 \mathrm{~km}$ (yaklaşık) mesafededir. İlerleyen bölümlerde, GNSS meteorolojisi ve reflektometresi teknikleri, GNSS istasyonu modelinin tasarım aşamaları ile sefer öncesi ülkemizde yapılan testleri ile Antarktika'ya kurulum süreci verilmiştir. Son bölümlerde ise, Antarktika gibi özel şartları olan bölgeler için tasarlanacak GNSS istasyonları için gerekli öneriler ve bulgular tartışılarak elde edilen tecrübelerin sonuçları irdelenmiştir.

\subsection{GNSS sinyalleri ile küresel iklim değişikliğinin izlenmesi}

GNSS sistemi, radyo dalgası gönderen aktif uydular ve bu uydulardan gelen sinyalleri toplayan donanımdan (anten ve alıcı) oluşan, Geomatik disiplininde son 40 yıldır efektif olarak kullanılan bir sistemdir. GNSS uydu sinyallerinin doğru sonuç vermesi için laboratuvar (vakum) ortamındaki gibi geometrik yol izlemesi ve gecikmemesi istenir. Buna karşın, GNSS sinyalleri gerek atmosfer içindeki farklı katmanlardan (iyonosfer ve troposfer) geçerken kırılarak ve/veya gerekse antene yakın yüzeyden ve yerden yansıyarak antene gecikmeli ulaşabilir. Bu istenmeyen durumlar GNSS ile konumlama çalışmalarında hata olarak kabul edilir ve düzeltilmesi yoluna gidilir. Son yıllarda ise, bu hata değerlerinin bir fonksiyonu olarak atmosferik parametre kestirimleri GNSS Meteorolojisi tekniği ve yansıyan yüzeylerdeki değişimler ise GNSS-R tekniği ile belirlenebilmektedir.

GNSS Meteorolojisi tekniği, troposferin izlenmesinde güvenilir, yüksek mekânsal ve zamansal çözünürlüklü bilgi üreten bir araç olarak kullanılmaktadır (Selbesoglu 2017). GNSS gözlemleri kullanılarak, atmosferde en yoğun bulunan sera gazı olan su buharı miktarı, radyosonde sistemi gibi geleneksel yöntemlere göre yüksek zamansal ve mekânsal çözünürlükle elde edilmektedir. Atmosferik su buharı, GNSS sinyallerinde yayılma gecikmesine neden olur ve buna Islak troposferik gecikme denir. Troposfer gecikmesi, sinyal yolu boyunca integral alınarak hesaplanır ve çeşitli modellerle zenit doğrultusuna izdüşürülür. Örneğin Viyana İzdüşüm Fonksiyonu (Boehm et al. 2006), uydu tabanlı jeodezik uygulamaları için yaygın olarak kullanılmaktadır. PWV (Precipitable water vapor: Yoğuşabilir su buharı miktarı), ıslak troposfer gecikmesinin dönüşüm faktörü ile çarpımı ile elde edilir. Dönüşüm faktörü, troposferin ağırlıklı ortalama sıcaklığına $\left(T_{m}\right)$ dayalı olarak hesaplanır (Bevis et al. 1992). $T_{m}$ ise, yeryüzünde ölçülen sıcaklık değeri kullanılarak ampirik modeller yardımıyla hesaplanır. Bu modeller bölgesel anlamda analiz edilerek katsayılarının güncellenmesi, su buharı miktarı kestirim doğruluğunu artırmaktadır. Bu doğrultuda, çalışma 
alanı için bölgesel katsayılar analiz edilerek su buharı elde etme doğruluğunun da artırılması hedeflenmiştir (Selbesoglu vd. 2019a). Ayrıca, GNSS tekniği ile uzun dönemli olarak troposferik su buharı miktarı izlenerek küresel iklim değişikliğinde büyük rol oynayan sera gazı etkisi de araştırılacaktır. İklim değişikliği izleme çalışmaları kapsamında deniz seviyesi ve kar/buz seviyesi değişimleri, GNSS sinyallerinin yansımaya uğrayan kısmını kullanarak yansıdığı yüzey hakkında bilgi sunan ve son yıllarda önemi daha iyi anlaşılan bir teknik olan GNSS-R ile gerçekleştirilecektir (Şekil 2) (Martin-Neira 1993, Larson et al. 2013, Lee et al. 2019, Selbesoglu vd. 2019b, Beşel ve Kayıkçı 2020).

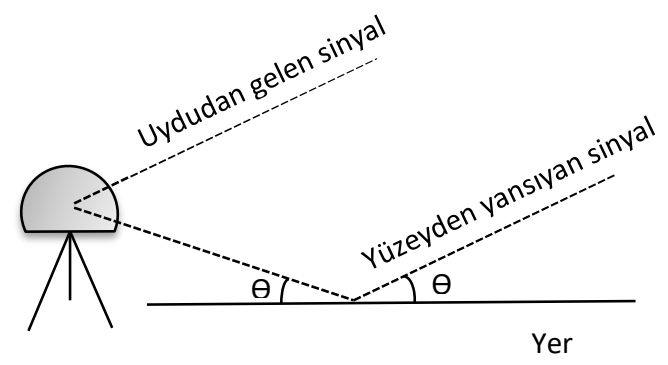

Şekil 2. GNSS-R tekniği geometrik gösterimi.

Yansımaya uğrayan sinyalin gücünde, yansıma yüzeyine bağlı olarak ve/veya faz, frekans ve genlik modülasyonu nedeniyle ve/veya yükseklik açısına bağlı olarak dalgalanmalar görülür. $\mathrm{Bu}$ dalgalanmalara ait girişim deseni, kod, faz ve özellikle SNR - Sinyal Gürültü Oranı (Signal to Noise Ratio) ölçmelerinde görülür. Geomatik çalışmalarda kullanılan jeodezik alıcılar (Right Hand Circularly Polarised (RHCP)), doğrudan gelen sinyalleri ve yansıyan sinyallerin girişimlerini ölçmektedir. Bununla birlikte, yansıyan verileri daha belirgin kılan ve doğrudan gelen sinyal ile yansıyan sinyali ölçmek için tasarlanmış çift antenli (Right Hand Circularly Polarised (RHCP)) ve Left Hand Circularly Polarised (LHCP)) antenler de kullanılabilmektedir (Larson et al. 2013, Santamaría-Gómez and Watson 2017).

Bu çalışma kapsamında kar/buz ve deniz seviyesi değişimleri, tesis edilen 2 farklı GNSS istasyonundan elde edilen gözlemlerle izlenecektir (Şekil 3-4). Yansıyan sinyali en iyi şekilde ölçmek için tasarlanan özel donanımlı çift anten yaklaşımıyla deniz seviyesi belirleme doğruluğun nispeten daha yüksek olması sebebiyle, TUR1 istasyonunda RHCP ve LHCP yapıda iki anten kullanılmıştır (Şekil 3).

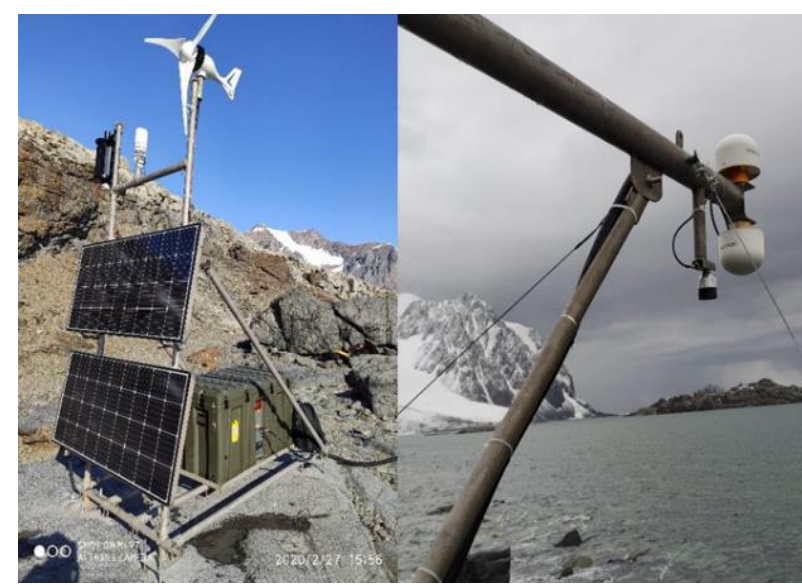

Şekil 3. TUR1 istasyonu.

Kar/buz seviye değişimlerinin deniz seviyesine göre daha yavaş olması ve sinyal yansıma karakteristiklerinden dolayı TUR2 istasyonunda ise RHCP yapıda tek anten kullanılmıştır (Şekil 4).

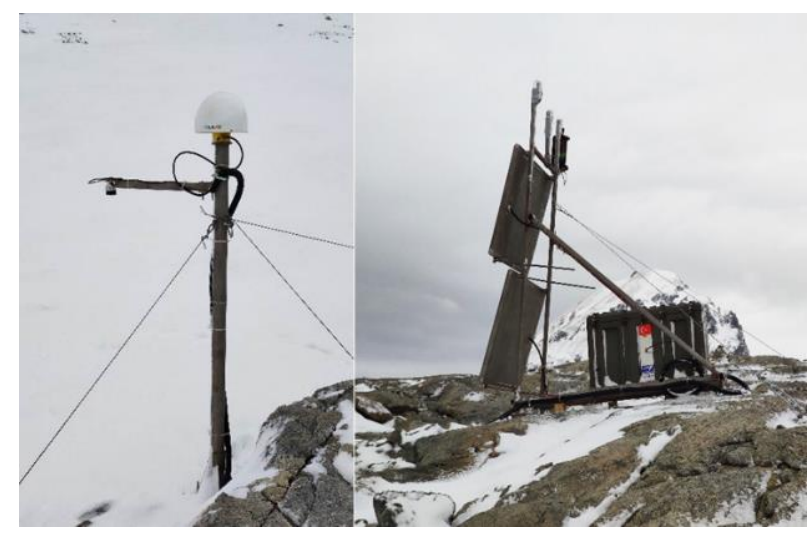

Şekil 4. TUR2 istasyonu.

Her iki istasyonda deniz ve kar/buz seviyesi değişimlerinin kontrolü için akustik sensörler ile de ilgili veri grubu toplanmaktadır. Ayrıca atmosferik parametrelerin bölgesel olarak izlenmesi için TUR1 istasyonuna otomatik meteorolojik istasyonu kurulmuştur.

İstasyonlarda bulunan GNSS alıcı ve antenleri choke ring yapıda jeodezik antenler olup, GPS, GLONASS, GALILEO ve BEIDOU uydu sinyal verilerini $0,2 \mathrm{~Hz}$ frekansında kayıt etmektedir. Ultrasonik sensörler ise $\% 0,4$ doğrulukla yükseklik değişimini ölçmektedir. Yersel meteorolojik veriler (Global radyasyon, nispi nem, sıcaklık, basınç, rüzgâr hızı ve 
yönü) ise $1 \mathrm{~Hz}$ frekansında ölçülmekte ve 10 dakikalık zaman periyodunda kayıt edilmektedir.

İlk veriler sefer dönüşüne geçilmeden hemen önce cihazlardan alınmıştır. TUR1 için 7 tam günlük TUR2 için ise 6 tam günlük veri seti elde edilmiştir. Elde edilen öncül sonuçlardan, GNSS verileri ile ultrasonik sensör verilerinin deniz seviyesi belirlemede uyumlu olduğu ve beklenilen doğrulukta seviye değişimlerinin belirlenebildiği görülmüştür. Kar seviyesi değişimlerinin belirlenmesi ise, seferin son günlerinde yağan kar yağışı sayesinde test edilmiş, ultrasonik sensör ile ölçülen değişim ile GNSS-R tekniği sonuçlarının uyumlu olduğu tespit edilmiştir (Selbesoglu vd. 2021).

\subsection{Antarktika'da GNSS istasyonu modeli ve kurulumu}

\subsubsection{Tasarım aşaması}

Antarktika'da sürekli gözlem yapan GNSS istasyonu kurmak ve işletmek oldukça zahmetli, maliyetli ve iyi planlanması gereken bir çalışmadır. İklim özellikleri açısından zorlu koşullara sahip bir bölge olduğu için istasyonların enerji, dayanıklılık gibi gereksinimleri büyük önem arz etmektedir. Bu bağlamda, çalışma kapsamında kurmayı planladığımız istasyonlar için tasarım parametrelerinin belirlenmesi oldukça önemlidir. Bu gereksinimler doğrultusunda, ideal tasarımı yapabilmek için kıtada daha önce yapılan çalışmalar araştırılmıştır. Kutup bölgelerinde kurulacak istasyonlar hakkında detaylı bilgi veren "Remote Station Technology" (Int Kyn. 3) başlığının altında yer alan proje ve raporlar ile POLENET (The Polar Earth Observing Network) ağında yer alan istasyonlara ait bilgilerden yararlanılmış ve istasyonların tasarımları, bölgeye göre optimize edilerek geliştirilmiştir. İstasyonların tasarımında öncelikle enerji ihtiyacını ve elektronik sistem detaylarını ortaya koymak için kapsamlı araştırmalar yapılmıştır. TUR1 ve TUR2 istasyonlarına ait enerji sistemi tasarımı sırasında öncelikle her bir istasyonun ihtiyaç duyduğu (tükettiği) enerji miktarı kullanılan ölçüm cihazlarına (GNSS alıcı, GNSS sensör, ultrasonik mesafe sensörü, meteoroloji istasyonu ve akü ped ısıtıcılar) ait adet, çalışma sıklığı ve çalışma güç oranı dikkate alınarak belirlenmiştir.
Sistemin, solar radyasyon şiddeti ve rüzgâr hızına bağlı olarak en yüksek seviyede enerji kazanımı elde edebileceği lokasyon, adanın bölgesel topoğrafik haritası üzerinde yapılan analizler ile gerçekleştirilmiştir. Ulusal bilim seferlerimiz kapsamında yapılan yersel ölçmeler ve insansız hava aracı ile yapılan lazer tarama verileri de bu modelleme çalışmalarında kullanılmıştır. İstasyon konumlarının belirlenmesi çalışmalarında, enerji kaynaklarının en verimli şekilde kullanılması ile çalışmanın amaçları doğrultusunda deniz seviyesi ve kar/buz seviyesinin başarılı bir şekilde izlenebilmesi, ayrıca, istasyon bileşenlerinin de şiddetli hava koşullarından daha az etkilenmesi hususları dikkate alınmıştır.

Ardından, belirlenen istasyonların konumlarına ait (Bkz. Şekil 1) saatlik iklim veri grubu Meteonorm programı kullanılarak üretilmiştir (Int Kyn. 4). Bu sırada Şekil 5 ile verildiği gibi paket program aracılığıyla kullanıcı tanımlı lokasyonlar oluşturulmuş ve bu lokasyonlara ait eğimli yüzeye düşen $\left(15^{\circ}\right)$ solar radyasyon şiddetinin (plane of array irridation, POA) kuzey yönü için yıllık toplam değeri $1367 \mathrm{kWh} / \mathrm{m}^{2}$ olarak belirlenmiştir. Ayrıca, dış ortam havasına ait yıllık ortalama sıcaklık $\left(T_{h}\right)$, rüzgâr hızı $\left(v_{r}\right)$ ve rüzgâr yönü $\left(y_{r}\right)$ değerleri sırasıyla $-4^{\circ} \mathrm{C}, 5,2 \mathrm{~m} / \mathrm{s}$ ve $233^{\circ}$ olarak bulunmuştur. Tüm bu iklim veri grubunun üretilmesi esnasında yeşil renk ile gösterilen iklim istasyonları tarafından ölçülen değerlerden yararlanılarak kullanıcı tanımlı istasyonlara (TUR1 ve TUR2) ait indirgenmiş değerler bulunmuştur. Program kütüphanesinde 6200 farklı şehirde toplam 8325 iklim istasyonu yer almaktadır ve Şekil 5 ile görüleceği üzere bu istasyonlar Antarktika kıtasında 6, Güney Atlantik okyanusunda 2 ve Güney Amerika kıtasının güney uç noktasında 3 adettir. POA ölçümü 1991-2010 yılları arasında, geri kalan iklim veri grubu ölçümleri ise 2000-2009 yılları arasında gerçekleşmiştir. 


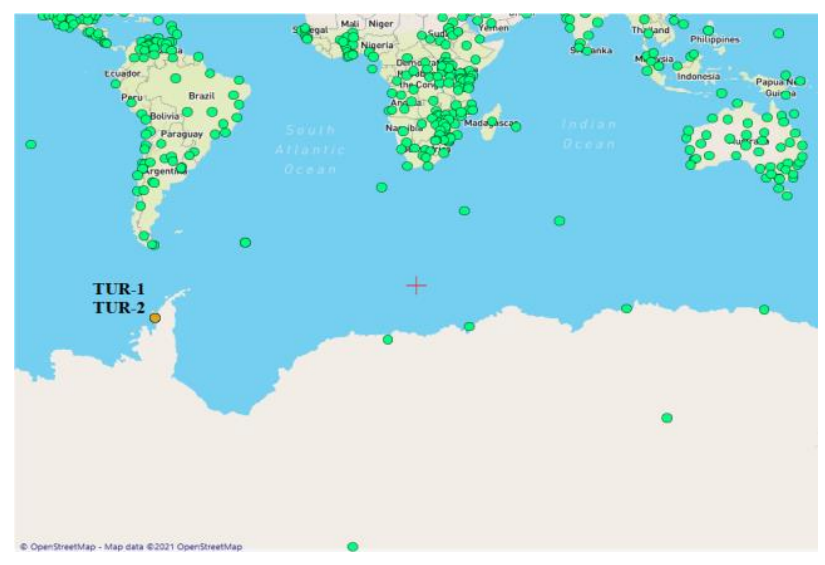

Şekil 5. TUR1 ve TUR2 istasyonlarının Meteonorm programında tanımlanması.

Meteonorm programı ile üretilen iklim veri grubu etkisi altında solar FV (Fotovoltaik) paneller ve rüzgâr türbinleri tarafından üretilebilecek, istasyonlara ait tüketimi karşılayabilecek enerji miktarı ise teorik olarak hesaplanmıştır. Bu esnada enerji depolama seçeneği de batarya kullanımı ile sisteme entegre edilmiştir. Rüzgâr türbinleriyle üretilebilecek enerji miktarı doğrudan üretici firmalar tarafından rüzgâr hızına karşılık sunulan performans grafikleri dikkate alınarak elde edilmiştir (Int Kyn. 5, Int Kyn. 6). Bu sırada türbinlerin devreye girme ve devreden çıkma hız aralığındaki değerler göz önünde bulundurulmuştur. Bunun neticesinde her bir istasyon için rüzgâr türbinleri ile yıllık toplam 400,4 kWh enerji üretimi potansiyelinin olduğu hesaplanmıştır. Solar FV teknolojisi ile üretilebilecek enerji miktarı ise aşağıda verilen eşitlik (1) kullanılarak $15^{\circ}$ eğim açısı ve $180^{\circ}$ azimut açıları altında hesaplanmıştır (Ozcan vd. 2019).

$E_{P V}=\eta_{F V} \cdot N \cdot A \cdot P O A \cdot P R$

Eşitlik (1) de yer alan $E_{P V}$ enerji üretimini (kWh), $\eta_{F V}$ panel verimini, $N$ panel sayısını, $A$ panel alanını $\left(\mathrm{m}^{2}\right)$ ve $P R$ performans oranını ifade etmektedir. Her iki istasyonda kullanılan panel adedi 2'dir ve her iki panel grubuna ait $P R$ değeri $D C / A C$ dönüşümü olmadığı için batarya kullanımı kaynaklı DC/DC dönüşümü göz önünde bulundurularak 0,9 alınmıştır. TUR1 ve TUR2 istasyonlarında kullanılan panellere ait $A$ sırasıyla $0,99 \mathrm{~m}^{2}$ (Int Kyn. 7) ve 1,29 $\mathrm{m}^{2}$ dir (Int Kyn. 8). POA değeri bu bölümün başında anlatıldığı gibi Meteonorm programı kullanılarak üretilmiştir (Int Kyn. 4). Son olarak $\eta_{F V}$ değeri aşağıdaki eşitlik yardımıyla belirlenmiştir (Ozcan vd. 2019).

$\eta_{F V}=\eta_{m p, r e f} \cdot\left(\begin{array}{c}1-\mu_{m p} \cdot\left(T_{\text {hüc }}-T_{\text {hüc,ref }}\right)+ \\ \delta \cdot \operatorname{In}\left(\frac{P O A}{\text { POA }_{\text {ref }}}\right)\end{array}\right)$

Eşitlik (2) de yer alan $\eta_{m p, r e f}$ maksimum güç noktası referans panel verimini, $\mu_{m p}$ güç sıcaklık katsayısını $\left(\% /{ }^{\circ} \mathrm{C}\right), T_{\text {hüc }}$ hücre sıcaklığını $\left({ }^{\circ} \mathrm{C}\right), T_{\text {hüc,ref }}$ referans hücre sıcaklığını $\left({ }^{\circ} \mathrm{C}\right), \delta$ solar radyasyon katsayısını ve $P O A_{\text {ref }}$ referans solar radyasyon şiddetini $\left(\mathrm{W} / \mathrm{m}^{2}\right)$ göstermektedir. Eşitlik (2) ile saha koşullarında meydana gelen sıcaklık ve solar radyasyon şiddetinin panel verimi üzerindeki etkisi ortaya konulmuştur. Her iki istasyonda tekli kristalin panel kullanımından ötürü $\mu_{m p} 0,037$ (URL-8), $\delta$ 0,052 (Slimani et al. 2017), $T_{\text {hüc,ref }} 25^{\circ} \mathrm{C}$ ve $P O A_{\text {ref }}$ $1000 \mathrm{~W} / \mathrm{m}^{2}$ alınmıştır. $T_{h u ̈ c}$ değeri ise aşağıda verilen Eşitlik (3) ile belirlenmiştir ( $D^{\prime}$ Orazio et al. 2013).

$T_{h \ddot{c} c}=T_{h}+k * P O A$

Eşitlik (3) de yer alan $k$ Ross katsayısıdır ve Antarktika koşulları dikkate alındığında modülün iyi bir şekilde soğutulması durumu için 0,02 alınmıştır (Skoplaki and Palyvos, 2009). Eşitlik (3) ile saatlik

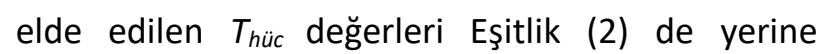
konulduğunda yine Antarktika koşulları için sadece 28 ve 48 saat sırasıyla TUR1 ve TUR2 istasyonlarında $T_{h u ̈ c}>T_{h}$ olduğu görülmüştür. Bu sebeple sadece solar radyasyon şiddetinin panel verimi üzerindeki etkisi incelenmiştir. Bir başka ifade ile $\mu_{m p} \cdot\left(T_{h u ̈ c}-\right.$ $T_{\text {hüc,ref }}$ ) değeri sıfır alınmıştır. Tüm bu kabuller altında solar FV teknolojisi ile üretilebilecek yıllık enerji miktarı TUR1 istasyonu için 469,5 kWh, TUR2 istasyonunu için ise 606,1 kWh olarak hesaplanmıştır. TUR1 ve TUR2 istasyonlarında kullanılan ölçüm cihazlarına bağlı ortaya çıkan yıllık enerji tüketim değerleri sırasıyla $71,1 \mathrm{kWh}$ ve 36,1 $\mathrm{kWh}$ bulunmuştur. Bu hesaplamalara göre, istasyonların toplam yıllık enerji ihtiyacının solar FV paneller ve rüzgâr türbinleri ile karşılanabileceği öngörülmüştür. 
Enerji ve ölçüm sisteminin belirlenmesi sonrasında mekanik iskeletin tasarımı ve bileşenlerin seçimi çalışmalarında, daha önce benzer yapıda GNSS istasyonları olan UNAVCO'nun teknik çizimleri ve ekipman bileşenlerinden faydalanılmıştır. Kullanılan malzemeler, Antarktika bölgesindeki iklim şartlarına (nem, rüzgâr, soğuk) uygun bir şekilde olması amacıyla detaylı olarak araştırıldıktan sonra tespit edilmiştir. İskelet, bölge koşullarına dayanıklı olan s316L kodlu çelikten üretilmiştir. Bahsedilen koşullarda uygulanabilirlik analizleri yapılarak takribi 1 ay içinde sonuca ulaşılmıştır. Bu aşamada, Horseshoe Adası üzerinde lojistiğin zorlu şartlarda ve çoğunlukla insan gücüyle gerçekleşeceğini bildiğimizden dolayı, taşıyıcı iskelet ve direkler tamamıyla modüler bir yapıda tasarlanmış ve üretilmiştir. Bağlantı elemanları, geçme sistem içine $14 \mathrm{~mm}, 16 \mathrm{~mm}$ civatalar sabitlenecek şekilde tasarlanmış ve kilitlenmesi de özel somun yapıştırıcılarla her bir civataya çift somun montaj edilecek şekilde planlanmıştır. Bu sayede, yüksek rüzgâr hızına bağlı olarak oluşacak titreşimin bağlantıları zayıflatması olasıı̆ı̆ en aza indirgenmiştir. Antarktika bölgesinde kurulumu yapılacak bölge bazalt kaya formunda olduğundan düz bir yüzey bulunması oldukça zordur. Bu sebeple, iskeletin ve direklerin yere sabitlenmesi, alt ve üstten ayarlanabilir civata-somun elemanları ile sabitlenecek yapıda oluşturulmuştur (Şekil 6).

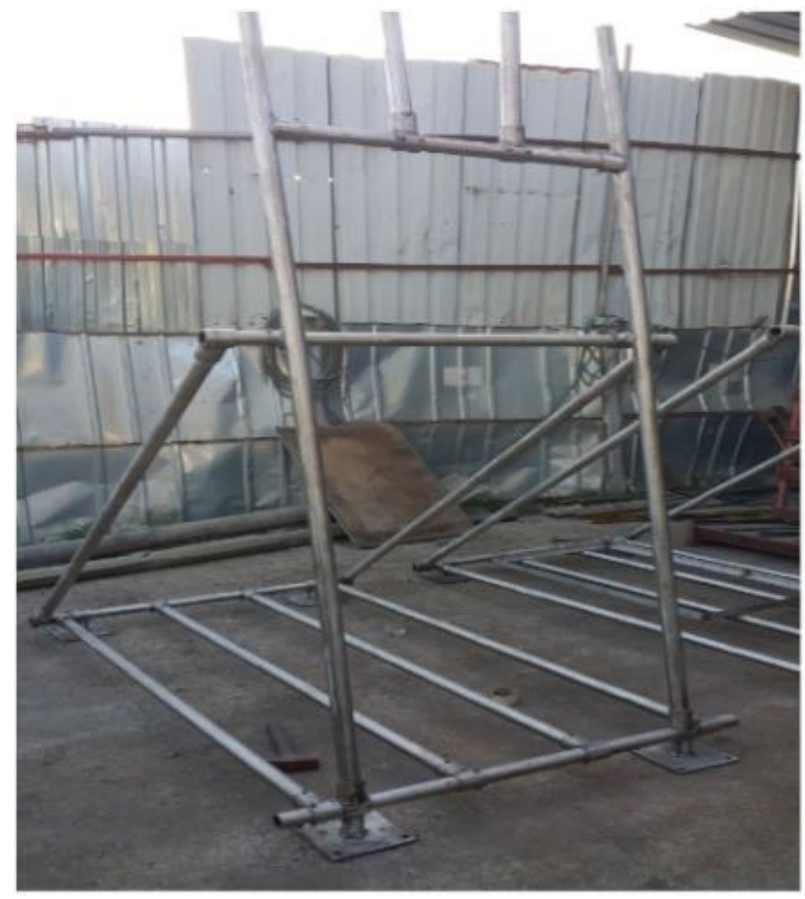

Şekil 6. Enerji sistemlerinin iskelet yapısı.
İstasyonların enerji birimleri ile elektronik alıcı ve regülatörlerle akülerinin muhafazası için askeri standartlarda üretilen, bölge koşullarına uygun ve MIL-STD-810G Çevre Testlerine göre test edilmiş taşıma sandıkları kullanılmıştır. Sandık içi izolasyon özel malzemelerle yapılmış ve $-50^{\circ} \mathrm{C}$ değerine kadar dayanıklı konnektörler kullanılarak kablo çıkışları kutu dışına aktarılmıştır. Aynı zamanda, sistemde ısıtıcı pedler kullanılmış, sandık içi sıcaklığı ölçen termostata bağlı olarak iç sıcaklığı $0^{\circ} \mathrm{C}$ değerinin altına düşmesine izin vermemek üzere devrede kalması tasarlanmıştır. Termostatın arıza yapmasına karşın ikinci bir kontrolcü termostat yerleştirilmiş ve bu şekilde sistemin güvenirliği artırılmıştır. Sistem içinin terleme yapmaması ve basınç regülasyonu amacıyla ise basınç valfli sandık tasarımı tercih edilmiştir. İstasyonların elektronik ve mekanik bileşenlerinin belirlenerek sistemin tasarlanması, 3 ay süren araştırmalar sonucunda gerçekleştirilmiştir. Bu kapsamda, yüksek rüzgâr hızına dayanımlı ve Antarktika bölgesi için özel üretilen rüzgâr türbini, mekanik montaj için gerekli malzeme ile donanım ve özel üretim gereken ölçme sistemleri 2-3 ay sürede tedarik edilmiştir.

\subsubsection{Test aşaması}

Bu aşamada, tüm bileşenler bir araya getirilip (özel jel akü, solar FV paneller, rüzgâr türbinleri, regülatörler), elektriksel montajları yapılarak test çalışmalarına başlanmıştır. Bu çalışma kapsamında, GNSS alıcl, anten ve enerji sistemleri gerekli izinler alınarak İstanbul Teknik Üniversitesi, Denizcilik Fakültesi, Tuzla kampüsüne saha testi yapılması amacıyla tesis edilmiştir (Şekil 7a ve 7b). Test alanında rüzgâr hızı 72 kilometre/saat $(\mathrm{km} / \mathrm{s})$ seviyelerine kadar zaman zaman ulaşmış, genellikle de 20 ila $60 \mathrm{~km} / \mathrm{s}$ dolaylarında seyretmiştir. Testler 2019 yılı Kasım ayından 2020 yılı Ocak ayına kadar devam etmiştir. Bu test çalışmalarında hava sıcaklığı bazı günlerde $-2,-3$ derece dolaylarına kadar düşmüştür. Sıcaklıklar, test aşamasının yapıldığı zaman diliminde -2 ile 12 derece aralığında değişmiştir. Bu sayede öncül testler farklı koşullar altında tekrarlı olarak gerçekleştirilmiştir. 

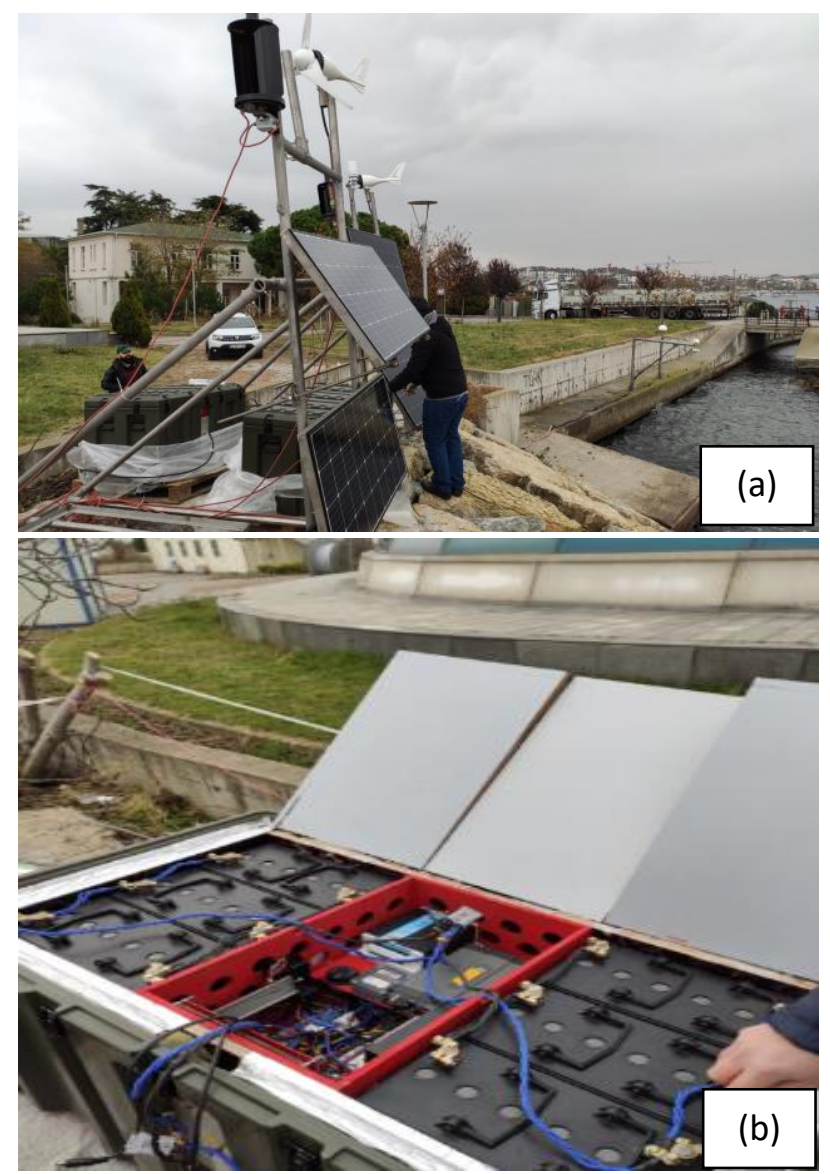

Şekil 7. Tuzla, Denizcilik Fakültesi iтü kampüsüne sistemlerin kurulmuş hali (a) Enerji sistemleri ve GNSS antenleri, (b) Sinyal alıcı ünite ve akülerin bulunduğu sistem bileşenleri.

Çalışmalar kapsamında takribi 1 ay süreyle ölçümler kayıt edilmiş, iki günde bir olmak üzere sahada veri, enerji, kablo, mekanik aksam ve diğer bileşenlerin çalışır durumda olup olmadığı raporlanmıştır. Bu süreçte gerekli görülen müdahaleler yapılmış ve istasyonların Antarktika iklim şartlarında çalışabilmesi için kablo izolasyonu, yüksek dayanımlı bağlantıların revize edilmesi, kullanılan bazı civata ve malzemelerin s316L çelik ile değiştirilmesi ve soğuk iklim şartlarına göre izolasyonun iyileştirilmesi işlemleri gerçekleştirilmiştir. Sisteme ait ultrasonik mesafe ölçerlerin, meteorolojik istasyonların, GNSS alıcılarının, sisteme enerji sağlayan akülerin, solar FV panellerin ve rüzgâr türbinlerin performansları test edilerek sistemin doğru bir şekilde çalışıp çalışmadığı izlenmiştir. Yapılan testler sonucunda sistemin enerji bileşenlerinin tasarımda öngörüldüğü şekliyle çalıştığı belirlenmiştir. Ayrıca, test aşamasında sistemin bütün detayları üzerinde çalışılmış (mekanik bağlantılar, elektrik bağlantıları, veri kayıt stratejileri, depolanan verilerin aktarımı), istasyonların kurulumunu yapacak araştırmacıların karşılaşabileceği sorunlara karşı bir iş akış planı oluşturulmuştur. Diğer yandan, Antarktika iklim koşullarının ağır olması ve buna bağlı olarak seferdeki çalışma günü sayısının değişkenlik gösterebilmesi sebebiyle sistemlerin kurulumu mümkün olan en kısa zamanda tamamlanması gerekmektedir. Bu amaçla, test aşamasında sistem kurulumu üzerine çalışmalar gerçekleştirilmiş, özellikle enerji bileşenlerinin kurulumu tekrarlanarak tecrübe elde edilmiştir.

\subsubsection{Antarktika, Horseshoe Adası'na kurulum aşaması}

Antarktika bölgesinde sürekli bir enerji kaynağının bulunmadığı düşünüldüğünde, enerji sistemlerinin tüm bileşenlerinin bir araya getirilerek (özel jel akü, solar FV paneller ve rüzgâr türbinleriyle birlikte elektriksel montajlarının yapılması) tesis edilmesi son derece önemlidir. Bununla beraber, GNSS antenleri ile ultrasonik sensörlerin kurulum lokasyonu, denize olan mesafesi ve yerden yüksekliği, GNSS-Reflektometresi ve GNSS meteorolojisi yöntemleri ile deniz seviyesi ve kar/buz seviyesi değişimleri ile troposferik su buharı miktarlarını belirlemede önemli ölçütlerdir (Selbesoglu vd. 2020). Meteorolojik istasyonun konumu ve yüksekliği de sıcaklık, basınç, nem, rüzgâr hızı, rüzgâr yönü, küresel radyasyon şiddeti ve yağış miktarı gibi parametreleri doğru ölçebilecek şekilde belirlenmelidir. Bu amaçla, 20 Şubat 2020 Perşembe günü istikşaf çalışmalarına başlanmıştır (Şekil 8). 


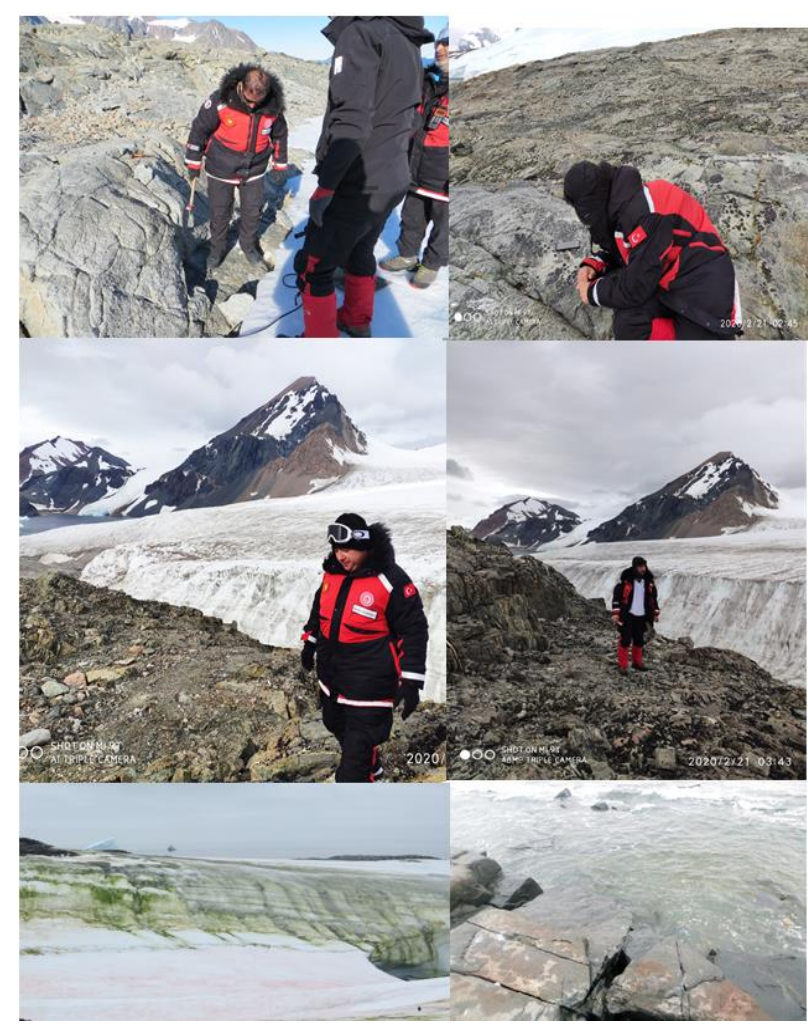

Şekil 8. İstikşaf çalışmalarından görüntüler.

İstikşaf çalışmaları, tasarım aşamasında belirlenen konumları da içerecek şekilde bir araştırmayı kapsamaktadır. Bu amaçla, 2 istasyon için daha önceden belirlenen 6 farklı konum, kayaç yapıları, topoğrafik durum ve enerji sistemi için uygunluk koşullarına göre incelenmiştir. 2 gün süre ile gerçekleşen bu çalışmada, meteorolojik koşullar, şebekeden bağımsız enerji sisteminin en sağlıklı şekilde güneş ve rüzgâr enerjisinden beslenmesi ve bölgede oluşabilecek buzul oluşumu ve kayaç parçalanması gibi jeolojik parametreler de göz önüne alınarak yapılmıştır. TUR1 istasyonu için sağlam kayanın bulunması, aynı zamanda kuzey batı yani arkada kalan kara bölgesinin buzul oluşumundan sonra koparak ayrılmalarından etkilenmemesi için 3 ayrı konum ayrıntılı olarak incelenmiştir. TUR2 istasyonu için de 3 farklı konumda incelemeler yapılmıs ve nihai konuma, meteorolojik koşullar, jeolojik yapı ve buzul izlenmesine elverişli bakış açısı parametreleri göz önüne alınarak karar verilmiştir. Bu aşamadan sonra, Antarktika Bölgesinde troposferdeki su buharı miktarı, deniz seviyesi değişimleri, kar ve buz seviyesi değişimleri izlenmesine olanak sağlayarak ülkemizi temsil edecek istasyonların kurulum çalışmaları başlamış ve 23 Şubat 2020 Pazar günü
TUR1 İstasyonu, 24 Şubat 2020 Pazartesi günü ise TUR2 İstasyonu Horseshoe Adasına tesis edilmiştir. İstasyonlardaki (TUR1 ve TUR2) rüzgâr türbini ve solar FV panellerinin ürettiği enerji her gün kontrol edilmiştir. Akü seviyesi her iki istasyon için de 3-4 gün içerisinde 14 volt gerilime ulaşmıştır. Enerji sistemlerimizin kontrolleri yapıldıktan sonra elektronik bağlantı şemasına göre bağlantılardaki gerilimler ayrı ayrı kontrol edilmiştir. Bu sayede her bir alıcı anten ve sensörde sürekli veri akışının sağlandığı belirlenmiştir. Ayrıca istasyonlardan her gün gemiye dönüş öncesi veriler bilgisayara aktarılmış ve gemide analizler yapılarak veri kalitesinde sorun olup olmadığı kontrol edilmiştir.

\section{Bulgular}

Bu çalışma kapsamında tasarlanan GNSS istasyonları ile meteoroloji istasyonu başarılı bir şekilde Antarktika, Horseshoe Adasına tesis edilmiş ve ilk veriler sefer dönüşüne geçilmeden hemen önce cihazlardan alınmıştır. Sefer dönüşü başlamadan son kontroller yapıldığında cihaz hafızalarına kayıt işleminin başarıyla devam ettiği görülmüştür. Öncül veriler ile yapılan analizlerde, TUR1 istasyonundan elde edilen 7 günlük GNSS-R tekniği sonuçlarının, ultrasonik sensör sonuçları ile yüksek doğrulukla uyumlu olduğu belirlenmiştir. Bununla beraber TUR1 istasyonunda, 7 gün boyunca su buharı miktarları da GNSS meteorolojisi tekniği ile belirlenmiş, meteoroloji istasyonundan alınan yağış miktarları ve TUR2 istasyonundan elde edilen 6 günlük su buharı miktarları ile karşılaştırılarak doğruluk analizleri gerçekleştirilmiştir. TUR2 istasyonundan ultrasonik sensör vasıtasıyla elde edilen kar/buz yüksekliği değişimlerinin, GNSS-R tekniği ile uyumlu olduğu gözlemlenmiştir. GNSS sinyalinin ıslak gecikme etkisi, Saastamoinen (1972) modeline dayalı olarak belirlenen kuru troposfer gecikmesinin toplam gecikmeden çıkarılmasıyla elde edilmiştir. Toplam troposferik gecikme miktarları ise, Bernese 5.2 bilimsel yazılımı kullanılarak elde edilmiştir (Dach et al. 2015). GNSS-R tekniği ile deniz ve kar seviye değişimlerinin tespiti, sinyal-gürültü oranı (SNR; Signal to Noise Ratio) tabanlı olarak yapılmıştır. Önümüzdeki seferler kapsamında kaydedilen verilerin alınması ile uzun dönemli 
analizler yapılacak, mevsimsel ve yıllık değişimler de tespit edilerek daha anlamlı yorumlar ortaya konulabilecektir. Ayrıca, Antarktika, Horseshoe Adasına ilk kez kurulan ve özellikle böylesine zorlu doğa koşullarının olduğu bir bölge için ilk kez tasarlanan bileşenleri itibariyle tüm istasyon yapılarının gelecek seferlerde izlenerek eksiklerinin belirlenmesi, oluşabilecek arızaların tespiti ve raporlanması ile bu konuda ulusal tecrübemiz daha da artacaktır. Özellikle Antarktika gibi uzak ve erişimi olmayan bölgeler için GNSS istasyonu, enerji sistemi ve mekanik tasarım gibi işlemlerin yapılması ve lojistiğinin sağlanarak sorunsuz halde tesis edilmesi için tüm koşulların düşünülmesi gerekmektedir.

\section{Tartışma ve Sonuç}

TUR1 ve TUR2 istasyonlarının Antarktika Horseshoe Adasına tesis edilmesi ile GNSS tabanlı tekniklerle küresel iklim değişiklerinin izlenmesi için ülkemiz adına ilk adım atılmıştır. Bu kapsamda, GNSS meteorolojisi ve GNSS reflektometresi teknikleri ile elde edilecek parametrelerin, Antarktika bölgesinin iklimsel karakteristiğini ortaya koymak için katkı sağlayacağı düşünülmektedir. Bu tekniklere dayalı olarak istasyonlardan elde edilecek uzun dönemli veriler ile Antarktika'da meydana gelen su buharı değişimleri, kar/buz kalınlık değişimleri, buzulların yer değiştirmeleri ve deniz seviyesi değişimleri izlenerek iklim değişimleri takip edilebilecektir. Ayrıca, GNSS istasyonlarının küresel dağılımı Antarktika bölgesinde zayıf olup, kurulan istasyonlar ile dağılımın iyileştirilmesine katkı sağlanarak buzullardaki değişimler, tektonik hareketler ve meteorolojik çalışmaların daha homojen dağılımlı veriler ile gerçekleştirilebileceği öngörülmektedir. Aynı zamanda bu istasyonlar, GNSS gözlemleri ile hassas ve yüksek doğrulukla konumlama yeteneğine sahip olup, bu bölgede yapılacak batimetrik haritalama, jeolojik ve jeofizik alanında yapılacak çalışmalar, gerçek zamanlı konumlama, navigasyon, coğrafi bilgi sistemi çalışmaları ve tektonik hareketlerin izlenmesi gibi konulara da oldukça önemli bilgiler sağlayabilecektir. Bu amaçlarla Antarktika'ya kurulan istasyonlar, tamamıyla yerli ve milli bir tasarıma sahip olup, kurulduğu bölge ve izlenen parametreler itibariyle de öncül bir çalışmadır. Bununla beraber, proje kapsamında gerçekleştirilen çalışmaların sonucu olarak, istasyonların tasarımından kurulumuna kadar milli olarak gerçekleştirebilme kabiliyetimiz anlaşılmıştır.

\section{Teşekkür}

Yazarlar, T.C. Cumhurbaşkanlığı himayelerinde, Sanayi ve Teknoloji Bakanlığı uhdesinde, TÜBiTAK MAM KARE koordinasyonunda düzenlenen Ulusal Antarktika Bilim Seferine teşekkürlerini sunar. Yazarlar, cihazların temini ve tasarımı aşamalarında destekleri için GNSS Harita Tek. Dan. San. Ve Tic. A.Ş' ne, Devimsel Elektronik, Mekatronik ve Bilişim Teknolojileri Sanayi ve Ticaret Ltd. Şti.' ne ve Mimar ibrahim Direk' e teşekkür ederler. Çizimler serbest lisanslı yazılımlarla üretilmiş olup akademik çalışmalara ücretsiz destek vermektedir.

\section{Kaynaklar}

Beşel, C. ve Kayıkçı, E., T., 2020. Türkiye denizlerinde GNSS reflektometre tekniği ile deniz seviyesi değişiminin araştırılması. Jeodezi ve Jeoinformasyon Dergisi, 8, 1, 1-17.

Bevis, M., Businger, S., Herring, T. A., Rocken, C., Anthes, R. A. and Ware, R. H., 1992. GPS meteorology: Remote sensing of atmospheric water vapor using the Global Positioning System. Journal of Geophysical Research: Atmospheres, 97(D14), 15787-15801.

Boehm, J., Werl, B. and Schuh, H., 2006. Troposphere mapping functions for GPS and very long baseline interferometry from European Centre for MediumRange Weather Forecasts operational analysis data. Journal of Geophysical Research: Solid Earth, 111(B2).

Dach, R., S. Lutz, P. Walser, P. Fridez (Eds); 2015: Bernese GNSS Software Version 5.2. User manual. Astronomical Institute, University of Bern, Bern Open Publishing. DOI: 10.7892/boris.72297; ISBN: 978-3906813-05-9.

D’Orazio, M., Di Perna, C. and Di Giuseppe, E., 2013. Performance assessment of different roof integrated photovoltaic modules under Mediterranean Climate. Energy Procedia, 42, 183-192.

Jayachandran, P., Hosokawa, K., Shiokawa, K., Otsuka, Y., Watson, C., Mushini, S., MacDougall, J.W., Prikryl, P., Chadwick, R. and Kelly, T. 2012. GPS total electron content variations associated with poleward moving Sun-aligned arcs. Journal of Geophysical Research: Space Physics, 117(A5).

King, M. A., Bevis, M., Wilson, T., Johns, B. and Blume, F., 2012. Monument-antenna effects on GPS coordinate 
time series with application to vertical rates in Antarctica. Journal of Geodesy, 86(1), 53-63.

Koulali, A. and Clarke, P., 2020. Effect of antenna snow intrusion on vertical GPS position time series in Antarctica. Journal of Geodesy, 94(10), 1-11.

Larson, K. M., Löfgren, J. S. and Haas, R., 2013. Coastal sea level measurements using a single geodetic GPS receiver. Advances in Space Research, 51(8), 13011310.

Lee, C. M., Kuo, C. Y., Sun, J., Tseng, T. P., Chen, K. H., Lan, W. H., Shum, C. K., Ali, T., Ching, K. E., Chu, P. and Jia, Y., 2019. Evaluation and improvement of coastal GNSS reflectometry sea level variations from existing GNSS stations in Taiwan. Advances in Space Research, 63(3), 1280-1288.

Li, F., Zhang, Q., Zhang, S., Lei, J. and Li, W., 2020. Evaluation of spatio-temporal characteristics of different zenith tropospheric delay models in Antarctica. Radio Science, 55(5), 1-16.

Li, M., Xu, T., Lu, B., \& He, K., 2019. Multi-GNSS precise orbit positioning for airborne gravimetry over Antarctica. GPS solutions, 23(2), 1-14.

Li, H., Wang, Z., Cui, X., Guo, J., Li, L. and Sun, B., 2020. The effect of the second-order ionospheric term on GPS positioning in Antarctica. Arctic, Antarctic, and Alpine Research, 52(1), 210-221.

Martin-Neira, M., 1993. A passive reflectometry and interferometry system (PARIS): Application to ocean altimetry. ESA journal, 17(4), 331-355.

Ozcan, H. G., Gunerhan, H., Yildirim, N. and Hepbasli, A., 2019. A comprehensive evaluation of PV electricity production methods and life cycle energy-cost assessment of a particular system. Journal of Cleaner Production, 238, 117883.

Pinat, E., Defraigne, P., Bergeot, N., Chevalier, J.-M., \& Bertrand, B., 2021. Long-Term Snow Height Variations in Antarctica from GNSS Interferometric Reflectometry. Remote Sensing, 13(6), 1164.

Richter, A., Popov, S. V., Fritsche, M., Lukin, V. V., Matveev, A. Y., Ekaykin, A. A., Lipenkov, V. Y., Fedorov, D. V., Eberlein, L., Schröder, L., Ewert, H., Horwath, M., and Dietrich, R., 2014. Height changes over subglacial Lake Vostok, East Antarctica: insights from GNSS observations. Journal of Geophysical Research: Earth Surface, 119(11), 2460-2480.

Santamaría-Gómez, A. and Watson, C., 2017. Remote leveling of tide gauges using GNSS reflectometry: case study at Spring Bay, Australia. GPS solutions, 21(2), 451-459.

Saastamoinen, J., 1972. Contributions to the theory of atmospheric refraction. Bulletin Géodésique (19461975), 105(1), 279-298.

Selbesoglu, M. O. (2017). Evaluation of Precipitable Water Vapor Derived From Global Navigation Satellite System Observations based on Troposphere Model. Feb-Fresenius Environ. Bull, 26, 3924-3929.

Selbesoglu, M. O., Yavasoglu, H. H., Karabulut, M. F., Gulal, V. E., Karaman, H. and Kamasak, M. E., 2018. Gnss Meteorolojisi ve Reflektometresi Teknikleri ile Antarktika Bölgesinin Troposfer ve Kar Kalinliğinin izlenmesi, Deformasyonlarin Belirlenmesi. 2. Kutup Bilimleri Çalıştayı, 22-23, 12 - 13 Eylül, İstanbul.

Selbesoglu, M. O., Yavasoglu, H. H., Karabulut, M. F., Gulal, V. E., Karaman, H. and Kamasak, M. E., 2019a. Gnss-Meteorolojisi ve Gnss-Reflektometresi Teknikleri ile Antarktika Bölgesinin Troposfer ve Kar Kalinliğinin İzlenmesi, Geliştirme Çalişmalari. 3. Ulusal Kutup Bilimleri Çalıştayı, 48-49, 5-6 Eylül, Ankara.

Selbesoglu, M. O., Yavasoglu, H. H., Karabulut, M. F., Gulal, V. E., Karaman, H. and Kamasak, M. E., 2019b. Monitoring the water vapor, snow/ice and sea level changes in the Antarctica with GNSS Meteorology and GNSS Reflectometry Techniques. XXIX International Symposium On: "Modern Technologies, Education And Professional Practice In Geodesy And Related Fields, 21, 05 - 06 November, Istanbul.

Selbesoglu, M. O., Yavasoglu, H. H., Karabulut, M. F., Gulal, V. E., Oktar, O., Ozsoy, B., Karaman, H. and Kamasak, M. E., 2020. Troposfer ve Deniz / Buz Seviyesi Reflektometresi Gözlem İstasyonlarinin 4. Türkiye Antarktik Bilim Seferi Kapsaminda Antarktika Horseshoe Adasi'na Kurulumu. 4. Ulusal Kutup Bilimleri Çalıştayı, 207-208, Online, 22-23 Ekim.

Selbesoglu, M. O., Yavasoglu, H. H., Karabulut, M. F., Gulal, V. E., Karaman, H., Kamasak, M. E., Oktar, O., and Ozsoy, B., 2021. Ground-Based GNSS Meteorology and Reflectometry Studies on Horseshoe Island during the 4th National Antarctic Science Expedition of Turkey: Installation and configuration of sea/ice level and water vapor monitoring stations. EGU General Assembly 2021, online, 19-30 Apr 2021, EGU21-15952.

Skoplaki, E. J. A. P. and Palyvos, J. A., 2009. Operating temperature of photovoltaic modules: A survey of pertinent correlations. Renewable energy, 34(1), 2329. 
Slimani, M. E. A., Amirat, M., Kurucz, I., Bahria, S., Hamidat, A. and Chaouch, W. B., 2017. A detailed thermal-electrical model of three photovoltaic/thermal (PV/T) hybrid air collectors and photovoltaic (PV) module: Comparative study under Algiers climatic conditions. Energy conversion and management, 133, 458-476.

Tabibi, S., Geremia-Nievinski, F., Francis, O. and van Dam, T., 2020. Tidal analysis of GNSS reflectometry applied for coastal sea level sensing in Antarctica and Greenland. Remote sensing of environment, 248, 111959.

Thomas, I. D., King, M. A., Bentley, M. J., Whitehouse, P. L., Penna, N. T., Williams, S. D., Riva, R.E.M., Lavallee, D.A., Clarke, P.J, King, E.C., Hindmarsh, R.C.A. and Kouvila, H., 2011. Widespread low rates of Antarctic glacial isostatic adjustment revealed by GPS observations. Geophysical research letters, 38(22).

Wang, J., Wu, Z., Semmling, M., Zus, F., Gerland, S., Ramatschi, M., Ge, M., Wickert, J. and Schuh, H., 2019. Retrieving precipitable water vapor from shipborne multi-GNSS observations. Geophysical research letters, 46(9), 5000-5008.

Whitehouse, P. L., Bentley, M. J., Milne, G. A., King, M. A. and Thomas, I. D., 2012. A new glacial isostatic adjustment model for Antarctica: calibrated and tested using observations of relative sea-level change and present-day uplift rates. Geophysical Journal International, 190(3), 1464-1482.

Wu, X., Heflin, M. B., Ivins, E. R. and Fukumori, I., 2006. Seasonal and interannual global surface mass variations from multisatellite geodetic data. Journal of Geophysical Research: Solid Earth, 111(B9).

Ye, L., Lay, T., Koper, K. D., Smalley Jr, R., Rivera, L., Bevis, M. G., Zakrajsek, A. F. and Teferle, F. N., 2014. Complementary slip distributions of the August 4, 2003 Mw 7.6 and November 17, 2013 Mw 7.8 South Scotia ridge earthquakes. Earth and Planetary Science Letters, 401, 215-226.

\section{internet kaynakları}

1-

https://kare.mam.tubitak.gov.tr/sites/images/kare_ma

m/ulusal_kutup_bilim_programi.pdf, (18.02.2021)

2-https://blog.gezgin.gov.tr/?p=2002, (20.02.2021)

3-https://www.unavco.org/projects/project-

support/polar/remote/remote.html, (21.02.2021) 5-https://www.prolectric.fr/micro-turbines/microturbine-forgen-v30-antarctique/, (22.02.2021)

6-https://www.istabreeze.com.tr/online/RuzgarTurbini/i500-12V-Ruzgar-Turbini-iSTA-BREEZE,

(22.02.2021)

7-https://www.enerjipazar.com/solar-gunespanelleri/perc-monokristal/190-watt-monokristalgunes-paneli-5-busbar-perc-hucre/, (23.02.2021)

8-

https://www.sharp.com.tr/cps/rde/xbcr/documents/do cuments/Marketing/Datasheet/1611_NQR256A_Mono_ BackContact_Datasheet_TR.pdf, (23.02.2021) 